\section{Planejamento familiar e laqueadura tubária: análise do trabalho de uma equipe de saúde}

\author{
Family planning and female sterilization: \\ analysis of work by a team of health providers
}

Clarice Marcolino 1

\section{Introdução}

This article presents partial results from a study aimed at recognizing the work of members of a public health team who regularly perform tubal ligations. Empirical data were obtained through interviews and observation of routine activities by nine team members. The principal analytical categories were health work concepts. The team was basically characterized as hierarchical, but the specific decision on surgical sterilization tended to become more horizontal, with a tendency towards a multidisciplinary approach. This situation tends to involve the ethical dimension, with a shift from scientific and biomedical knowledge to the social sciences and humanities. On the other hand, and in a contradictory way, in the actual decision to perform surgical sterilization, technical criteria are supported by biomedical knowledge, and comprehensive knowledge is relegated to a secondary role.

Tubal Sterilization; Patient Care Team; Women's Health; Family Planning
Os dados estatísticos sobre a prevalência do uso de métodos contraceptivos no Brasil mostram que, do total de $76,7 \%$ de mulheres em união consensual, 70,3\% usam métodos contraceptivos modernos. Destas, $40,0 \%$ estão esterilizadas, $21,0 \%$ usam pílula anticoncepcional, $4,4 \%$ usam condom, $2,4 \%$ utilizam outros métodos, $6,0 \%$ recorrem a métodos tradicionais (abstinência periódica e coito interrompido) e $6,0 \%$ recorrem à esterilização masculina 1 .

Esses dados sobre a prevalência da anticoncepção nos mostram que as mulheres brasileiras entre 15 a 45 anos de idade, na sua maioria, usam métodos anticoncepcionais, dentre os quais a esterilização cirúrgica e a pílula são os mais utilizados.

Até 1997, a esterilização não era recomendada, promovida e nem regulamentada pelo Ministério da Saúde e só podia ser feita no caso de riscos de vida para a mãe, exigindo autorização consubstanciada que demonstrasse a necessidade de sua realização.

Em 1997, o Ministério da Saúde, por meio da Portaria no 1442 e, posteriormente, da Portaria no 0483 incluiu a laqueadura tubária e a vasectomia no grupo de procedimentos cirúrgicos do Sistema Único de Saúde (SUS), permitindo a esterilização nas seguintes situações: no caso de homens e mulheres maiores de 25 anos ou com pelo menos dois filhos vivos, e no 
caso de risco para a mãe ou para o filho, tendo testemunhado em relatório escrito e assinado por dois médicos, observando um prazo mínimo de 60 dias entre a manifestação da vontade do casal e a realização da cirurgia.

A legislação brasileira exige que os serviços de saúde que realizam a esterilização ofereçam atendimento multiprofissional, informação e acesso a todos os métodos contraceptivos, desencorajando a esterilização precoce.

Os profissionais da saúde têm papel importante no processo de decisão da mulher pela esterilização feminina. Há uma multiplicidade de fatores envolvendo a escolha da esterilização, e os médicos têm uma posição importante na influência dessa decisão 4 .

A literatura consultada sobre a laqueadura de trompas aborda questões relacionadas aos fatores determinantes ligados à decisão da mulher pela cirurgia esterilizadora; entretanto, é pouco discutida a estruturação das equipes de saúde como base da organização dos serviços de planejamento familiar e do seu impacto na escolha dos métodos contraceptivos, particularmente a laqueadura tubária.

As equipes multiprofissionais têm sido apontadas como capazes de minimizar os problemas da fragmentação do trabalho em saúde advindos da crescente especialização dos profissionais dessa área nas últimas décadas. Essa recomendação é feita no intuito de melhor resolver os problemas de saúde e reduzir a alienação desses profissionais em relação às suas práticas 5 .

A acentuada divisão do trabalho no setor de saúde remete-nos à divisão técnica do trabalho, própria do modo de produção capitalista.

A divisão técnica do trabalho introduziu o fracionamento de um mesmo processo de trabalho, derivando outros trabalhos parcelares e os aspectos de complementaridade e interdependência entre eles.

O processo de divisão do trabalho em saúde determinou uma gama de trabalhadores da área da saúde, especialistas em determinada área.

Inicialmente, o médico desempenhava todas as funções do processo de trabalho, relacionadas ao diagnóstico e à terapêutica, e muitas vezes à assistência direta ao cliente. Com a complexidade do conhecimento, a ampliação da infra-estrutura institucional, outros trabalhadores vão se agregando a este trabalho, que passa a ser coletivo 6. "Assim, a divisão do trabalho caracteriza-se pelo processo de divisão interna do trabalho médico, constituindo as especialidades médicas; pelo desdobramento do trabalho médico em atividades assumidas por outros agentes, tais como enfermagem; e pela agrega- ção de outros profissionais com áreas complementares, como psicologia, serviço social e outros" (Mendes-Gonçalves 1992 apud Peduzzi 7 p. 29).

O médico, historicamente, deteve o controle do processo de trabalho. A hegemonia médica reflete a apropriação do capital científico da área da saúde. O maior ou o menor domínio intelectual de cada intervenção técnica se traduz em valoração desigual dos profissionais de saúde, estabelecendo relações desiguais ou hierárquicas 7 .

Isso posto, retomamos a idéia de que o trabalho em equipe é uma possibilidade de recomposição dos vários trabalhos dos profissionais da área da saúde na busca de eficiência e efetividade na sua execução, com a finalidade de atender às necessidades de saúde dos usuários.

Neste estudo, o objetivo foi reconhecer as especificidades do trabalho da equipe de saúde que toma a laqueadura como alvo de intervenção.

\section{Cenário do estudo}

A instituição escolhida para realizar o trabalho foi uma entidade filantrópica não governamental, sem fins lucrativos, cuja missão é prestar assistência integral à saúde da comunidade, sobretudo na área materno-infantil, incluindo o planejamento familiar.

As cirurgias de esterilização feminina são financiadas pelo SUS e pelas doações à Associação Comunitária de Amigos e Usuários da instituição.

\section{Metodologia}

Nesta investigação qualitativa a coleta de dados foi realizada por meio de entrevistas, seguindo um roteiro que visou apreender o ponto de vista dos entrevistados sobre o objeto de estudo. Partimos do trabalho da equipe envolvida com a cirurgia esterilizadora, no seu contexto de exercício cotidiano, e constatamos como os profissionais a operacionalizam.

Foram entrevistados nove profissionais da equipe de saúde: assistente social, agente de saúde, enfermeiras, médicos e psicólogos.

Os discursos foram submetidos à análise, segundo a orientação da técnica proposta por 8 e adaptada por 9 .

Para ordenar os dados segundo a orientação desses autores, inicialmente fizemos várias leituras dos discursos, tentando familiarizarnos com o texto, buscando apreender os temas 
subjacentes aos discursos. Num segundo momento, voltamos a ler o texto, desta vez, assinalando todas as figuras. Em seguida, estabelecemos o encadeamento entre temas e figuras; no passo seguinte, fizemos a recomposição, por meio de "frases temáticas", que sintetizam os temas e subtemas do discurso em sua totalidade; finalmente, sintetizamos as frases temáticas, agrupando-as e categorizando o material empírico.

As categorias empíricas estabelecidas com base na análise dos discursos foram examinadas à luz do contexto de prática e ação, ou seja, da dinâmica da base material da prática e das categorias analíticas: divisão do trabalho, complementaridade, interdependência, tecnologias (saberes e instrumentos). A análise dos dados ancorou-se também em estudos já realizados por outros pesquisadores, especialmente aqueles relacionados à temática aqui discutida $7,10,11,12,13,14,15$.

A observação foi uma técnica auxiliar utilizada com a finalidade de ampliar as perspectivas de compreensão do objeto de estudo. Foi utilizada de forma complementar na análise de dados para explicitar alguma passagem, em particular.

O resultado apresentado é parte da tese de doutorado da autora 4 e aborda uma das categorias empíricas analisadas - o trabalho da equipe de saúde acerca da laqueadura tubária.

\section{Resultados}

\section{O trabalho da equipe de saúde}

A atenção à saúde da mulher em geral, o planejamento familiar e a contracepção cirúrgica em particular constituem projetos a serem desempenhados pela equipe de saúde.

As frases temáticas a seguir mostram essa forma de organização do trabalho. Vejamos:

- "O planejamento familiar é desempenhado por equipe multidisciplinar composta por psicólogo, assistente social, enfermeira, auxiliar de saúde e técnica de enfermagem".

- "O médico atua como coordenador da equipe e como cirurgião, realizando salpingotripsias e fazendo inserção de DIU".

Verificamos que, na organização geral do trabalho da equipe, o médico detém um espaço de poder, uma vez que se posiciona como coordenador da equipe de saúde da mulher, e os outros profissionais se agregam à equipe, caracterizando-a como uma equipe hierarquizada. A centralidade está no trabalho médico, visto que lhe cabe a ação diagnóstica e terapêu- tica. O trabalho dos demais profissionais constitui um trabalho complementar, interdependente e algumas vezes articulado.

Mostramos como é a organização geral do trabalho da equipe. Agora vamos apontar outro aspecto da organização do trabalho da equipe que ocorre em torno da decisão sobre a aprovação da cirurgia esterilizadora: o da interação entre os profissionais da equipe.

As frases temáticas extraídas dos discursos dos depoentes mostram aspectos do trabalho em equipe relacionado à comunicação e à interação entre os agentes:

- "Os profissionais envolvidos na equipe de planejamento familiar têm interesse e dedicação".

- "A equipe multiprofissional reúne-se uma vez por semana para discutir, avaliar e tomar decisões sobre pedidos de ligadura que o serviço psicossocial tenha dúvidas em relação à autorização".

- "A qualidade do trabalho da equipe multiprofissional envolvida com a vasectomia e ligadura de trompas difere de outros de maneira geral, porque leva em consideração muitos outros aspectos além dos critérios idade e número de filhos".

- "As discussões da equipe envolvem a reflexão sobre os papéis da mulher na sociedade, em particular a dependência financeira do homem e de ir além das questões da maturidade".

A comunicação e o diálogo são instâncias fundamentais para a integração de atividades. Esse diálogo entre os profissionais contempla a dimensão técnica, relacionada às atividades, aos procedimentos e a todos os instrumentos necessários para atingir a finalidade da prestação de cuidados, e a dimensão ética, que não se reduz ao relacionamento interpessoal, mas se preocupa em conhecer, reconhecer e considerar o trabalho dos demais, seja da mesma área de atuação, seja de outras 7 .

Verificamos que, além de cumprir o propósito de tomar decisões acerca de pedidos de ligadura, a equipe aponta outros aspectos que indicam a superioridade do trabalho em equipe, à medida que estimula a criatividade e o intercâmbio de idéias. Os profissionais mostraram interesse e envolvimento com a tarefa de discutir e avaliar as solicitações de esterilização tubária. Ao colocarem como horizonte a ampliação do objeto de intervenção para além da esfera biológica, nossos entrevistados, visam à multidimensionalidade do objeto de trabalho e à possibilidade de rearticulação dos trabalhos especializados. Esta última se apresenta como possibilidade, uma vez que não foi mencionada como objetivo do trabalho da equipe de saúde. 
Para Campos 5, a organização parcelar do trabalho desvincula os profissionais do produto final que se pretende alcançar em um projeto ou programa que vise à promoção, prevenção ou reabilitação da saúde. "O trabalhador encontra-se, portanto, separado de sua 'obra'. Na saúde é preciso reaproximar os trabalhadores do resultado de seu trabalho" 5 (p. 235).

Para que tal orientação se realize, é preciso envolver todos os participantes no "projeto", de modo que passem à condição de sujeito, reconhecendo-se como parte da "obra" ou do seu trabalho.

É fundamental a constituição e a coordenação de uma equipe multiprofissional unificada e comprometida com um plano de trabalho. Esse projeto assistencial constitui uma referência para a equipe de trabalho que o elaborou; no entanto, é preciso aproveitar melhor esses momentos, a fim de construir um projeto assistencial comum valendo-se de interações e trocas.

No caso da tomada de decisão acerca da laqueadura tubária, os participantes da equipe têm ido além dos aspectos biomédicos da atenção à saúde da mulher e do planejamento familiar, permitindo uma aproximação que apreenda a complexidade e a multidimensionalidade das necessidades de saúde nessa área. Assim, no caso da decisão pela laqueadura tubária, e somente neste caso particular, o modelo hierarquizado de trabalho em equipe parece não ser o modelo nuclear, no qual o trabalho do médico é o centro e os demais são periféricos.

Apesar de as condições que propiciam a integração dos trabalhos especializados estarem presentes na organização do serviço estudado, a possibilidade de integração se mostrou frágil, apontando para a necessidade da equipe organizar-se com base em um projeto assistencial comum que permita trocas intersubjetivas entre os profissionais e usuários, ou dos profissionais entre si.

A equipe avança com o intento de ser um grupo interativo tendendo à horizontalização; entretanto, é a racionalidade biomédica ainda nuclear no processo decisório. Esse destaque é importante porque, como veremos a seguir, na discussão sobre o trabalho dos profissionais da equipe, ele se caracteriza como hierarquizado.

\section{O trabalho da equipe de saúde no planejamento familiar: o papel dos profissionais da equipe}

Fundamentados na análise das entrevistas, depreendemos que o trabalho se organiza de forma parcelar e está relacionado a um produto final atenção à saúde da mulher e ao planejamento fa- miliar. O conjunto de ações é desenvolvido por uma equipe de saúde, mas não em equipe.

Passemos à análise de como cada um vê seu trabalho e o trabalho conjunto e como estes se revelam no processo de trabalho.

A centralidade no trabalho médico permanece, já que lhe cabe a ação diagnóstica, terapêutica, cirúrgica e de coordenação da equipe.

As frases temáticas a seguir mostram atividades desenvolvidas por esse profissional da equipe.

- "O médico atua como coordenador da equipe e como cirurgião, realizando salpingotripsias e fazendo inserção de DIU".

- "Na consulta médica, são reforçados pontos sobre o método escolhido, sobre a ativação do método e fornecidas orientações sobre o sistema reprodutivo".

O trabalho dos demais profissionais é um trabalho complementar, interdependente, delegado em graus de complexidade diferentes, ora integrado, ora desarticulado.

Para que o médico execute o seu trabalho de diagnóstico, de terapêutica e de intervenção, ele necessita do trabalho de outros.

Observamos que o trabalho do médico e o da enfermeira estão, predominantemente, direcionados pelo modelo clínico.

O principal instrumento de trabalho da enfermeira no planejamento familiar é a consulta de enfermagem.

As frases temáticas a seguir evidenciam o trabalho desempenhado pelas enfermeiras:

- "No planejamento familiar, a enfermeira faz orientação individual, consulta de enfermagem com prescrição de métodos, inserção de DIU, prevenção de câncer de colo e mamas, atende retornos e revisões de DIU, de laqueadura e de outros métodos".

- "A enfermeira, ao realizar o atendimento individual de mulheres, fornece-lhes o método escolhido (pílula ou preservativo); faz a revisão $e$ retirada de DIU; coleta material para prevenção de câncer do colo de útero e orienta sobre a importância do controle".

- "A enfermeira participa das discussões da equipe de planejamento familiar".

Verificamos que a assistência de enfermagem no planejamento familiar é uma assistência individualizada que tem como único objeto o corpo anátomo-funcional; aproxima-se do trabalho médico, adquire valor e libera o médico para atividades de diagnóstico e tratamento, a saber, libera o médico para atividades mais complexas. Outras vezes, a consulta de enfermagem é representada como forma de ampliar a cobertura assistencial do planejamento familiar como aponta um dos entrevistados: 
- "O enfermeiro, fazendo o planejamento familiar clínico, tem permitido maior acessibilidade da população aos métodos contraceptivos".

Há uma racionalização do trabalho de assistência à saúde da mulher separando as atividades em graus de complexidade, o que permite que a oferta de determinadas ações possa ser ampliada a um custo menor, graças à delegação de funções.

Apesar de a enfermeira realizar, em parte, um trabalho complementar e buscar muitas vezes um atendimento integral, a sua assistência não é bem aceita pela comunidade, que, não raro, se opõe a certas atividades que realiza.

Peduzzi 7 (p. 172) ressalta que "o modelo biomédico coloca o saber não médico como algo periférico e ideologicamente instala uma hierarquia de valores que faz crer como saber periférico, como saber desprovido de tecnicidade". Notamos que isso repercute na comunidade.

Os agentes da equipe, como os psicólogos, a assistente social e a agente de saúde, realizam atividades voltadas para a saúde das pessoas, considerando além dos aspectos biológicos, os aspectos psicológicos e sociais envolvidos no processo saúde/doença.

Os psicólogos atuam na assistência à saúde da mulher desenvolvendo cursos ou grupos de gestantes, cuja temática é o planejamento familiar e a contracepção; oferecem também orientação sexual para mulheres que vão se casar. Fazem palestras no puerpério incluindo, dentre outros assuntos, o planejamento familiar. Fazem palestras sobre planejamento familiar e AIDS para escolares de primeiro grau nas escolas da região.

Vejamos algumas frases temáticas dos entrevistados que apontam as atividades desenvolvidas pela assistente social e pelos psicólogos.

- “A psicóloga faz palestras para puérperas, incluindo, dentre outros, o planejamento familiar e contracepção".

- "A psicóloga desenvolve trabalho com grupo de gestantes no ambulatório, orientando-as de acordo com as necessidades e interesses e sempre inclui o planejamento familiar".

- "O psicólogo participa do curso de gestantes e orienta sobre planejamento familiar".

O trabalho da assistente social e dos psicólogos apresenta pontos de articulação, tanto que eles se colocam como trabalhadores do setor psicossocial, cuja função, dentre outras, é avaliar e definir a realização do procedimento da laqueadura/vasectomia, ou encaminhar o cliente para avaliação da equipe de saúde. O serviço psicossocial tem o poder de decidir sobre a aprovação da cirurgia esterilizadora. Isso não significa que a avaliação que precede à aprova- ção da cirurgia seja feita somente pelo serviço psicossocial. Na maioria das situações, é encaminhado por outros profissionais e, quando há dúvidas sobre a aprovação da cirurgia, o caso é discutido com a equipe de saúde.

Como membros da equipe de saúde, os psicólogos avaliam homens e mulheres que querem se submeter à vasectomia ou ligadura de trompas, verificando os aspectos relacionados ao campo do emocional, especialmente quanto à maturidade emocional para encerrar a vida reprodutiva; atuam também de forma preventiva, levantando situações que pressionam a mulher a fazer ligadura, como mulher jovem que sofre pressão da família, mãe solteira que sofre pressão do pai, relacionamento conjugal conturbado e mulher abandonada pelo marido.

Vejamos algumas frases temáticas que apontam as atividades relacionadas à ligadura de trompas e vasectomia, desenvolvida por esses dois profissionais.

- "No setor psicossocial, a assistente social elou o psicólogo avaliam e definem a realização do procedimento de laqueadura/vasectomia ou o encaminhamento para a equipe".

- "O serviço de psicologia faz uma avaliação das mulheres que desejam fazer a ligadura de trompas. Em caso de dúvidas, elas são enviadas para o serviço social para uma reavaliação. $\mathrm{Ou}$ tras vezes ainda, o caso necessita ser discutido pela equipe multidisciplinar para posterior tomada de decisão".

- "Como membro da equipe de planejamento familiar, a psicóloga desenvolve um trabalho de ficar na escuta das questões relacionadas ao campo do emocional, principalmente quanto à maturidade emocional para encerrar a vida reprodutiva, tanto de homens quanto de mulheres que desejam submeter-se à cirurgia esterilizadora".

A agente de saúde atua no serviço e na comunidade. No serviço, ela faz entrevista com a clientela, para coletar dados relacionados à vida e à saúde familiar e reprodutiva da mulher. É a etapa de identificação do atendimento individual. A agente de saúde também faz palestras e orientações no serviço e na comunidade sobre planejamento familiar, com demonstração de métodos contraceptivos, suas vantagens, desvantagens, além de orientar sobre aleitamento materno e higiene.

Vejamos as frases temáticas que revelam essas atividades:

- "A agente de saúde faz entrevista com a mulher, preenchendo uma ficha com dados relacionados à sua vida e saúde familiar e reprodutiva e sobre sua ocupação; faz palestras e orientações na comunidade". 
- "A agente de saúde faz visita domiciliar e orienta grupos de gestantes na comunidade sobre aleitamento materno, planejamento familiar, informações sobre os serviços que oferecem o planejamento familiar, demonstração dos métodos contraceptivos, suas vantagens e desvantagens, sobre higiene e outros assuntos de interesse da comunidade".

Estudos realizados por Schraiber et al. $16 \mathrm{e}$ Scharaiber \& Peduzzi 10 apontam que a idéia de recomposição dos trabalhos na direção da integralidade da atenção não tem se mostrado possível apenas pela presença de diferentes profissionais realizando ações. É necessário articulação das ações e comunicação interprofissional.

\section{O trabalho da equipe na laqueadura tubária: o aconselhamento}

O aconselhamento é particularmente importante no caso da esterilização, por se tratar de um método cirúrgico que tem efeito permanente. Essa é a orientação seguida pela equipe multiprofissional estudada. $\mathrm{O}$ aconselhamento representa um espaço para a comunicação cliente-membro da equipe, no qual tanto os clientes quanto os profissionais de saúde escutam e falam.

Vejamos algumas frases temáticas que demonstram essa forma de desenvolver o trabalho. - "A função do profissional é colocar todas as questões que envolvem a laqueadura para que a mulher possa refletir e tomar uma decisão consciente e amadurecida".

- "A psicóloga não indicaria a ligadura para ninguém, mas ajuda a pessoa a tomar decisões por meio de informações, troca de idéias, numa relação de ajuda para que o outro possa tomar a própria decisão de maneira tranqüila e saudável".

Esclarecer a mulher quanto a assumir os riscos e conseqüências da cirurgia esterilizadora, depois que ela já está informada e orientada, é imperativo no trabalho da equipe envolvida com a esterilização cirúrgica. $\mathrm{O}$ aconselhamento é a atividade que garante um suporte para a tomada de decisão da mulher.

Vejamos algumas frases temáticas que apontam essa diretriz.

- "A mulher deve submeter-se à laqueadura de trompas somente após estar esclarecida e ciente sobre a cirurgia, bem como disposta a assumir os riscos que dela possam advir".

- "Os profissionais de saúde devem evitar que as mulheres tomem decisões precipitadas sobre a cirurgia esterilizadora, orientando-as sobre os riscos e as conseqüências da cirurgia".

- "A mulher ou o homem devem estar tranqüilos, conscientes, bem informados e emocionalmente amadurecidos sobre decisão pela ligadu- ra ou vasectomia, para evitar problemas posteriores".

Graças ao aconselhamento, pode-se evitar ou cancelar decisões equivocadas de clientes mal informadas ou tomadas em circunstâncias difíceis.

A frase temática extraída de uma das entrevistas mostra essa possibilidade:

- “O psicólogo já deparou com situações em que, após o atendimento, a pessoa desistiu da laqueadura".

Para os profissionais da equipe multiprofissional, o arrependimento é a complicação mais importante que se deve tentar evitar, e o processo de avaliação da equipe para a tomada de decisão influencia para um baixo índice de arrependimento.

As frases temáticas abaixo nos remetem a essa preocupação.

- “O médico considera que o arrependimento é a complicação mais importante na laqueadura de trompas e que se deve tentar evitar".

- "O processo de avaliação da equipe para a tomada de decisão sobre a realização da laqueadura/vasectomia influencia no baixo indice de arrependimento".

$\mathrm{O}$ aconselhamento na laqueadura tubária, como trabalho interativo desenvolvido por todos os membros da equipe, tenta apreender um complexo de conhecimentos gerados pela própria natureza do objeto. A perspectiva de multidimensionalidade que a equipe tenta imprimir ao trabalho de aconselhamento inclui, além do aspecto biológico, a perspectiva psicológica e emocional presente no processo de decisão pela laqueadura tubária. Os profissionais mencionam a necessidade de ficarem na escuta de questões relacionadas ao campo do emocional, especialmente quanto à maturidade para encerrar a vida reprodutiva.

Nossos entrevistados apontaram ainda para a importância de se ficar atento para a relação entre ligadura de trompas, vida sexual e reprodução.

Vejamos as frases temáticas que incluem essa perspectiva:

- "A psicóloga considera que se deve atentar para a relação entre a ligadura e a vida sexual".

- "Na experiência de trabalho do psicólogo, a relação ligadura de trompas, reprodução e sexualidade deve ser vista com cuidado, por causa dos efeitos psicológicos negativos que essa cirurgia pode causar sobre a sexualidade da mulher e no relacionamento do casal".

Um dos principais recursos utilizados para o aconselhamento é a informação, que é transmitida por intermédio de palestras educativas em grupo e, também, de orientações individuais. 
A informação é uma atividade praticada por todos os agentes da equipe multiprofissional e não constitui atividade específica de determinado agente da equipe, embora seja feita, predominantemente, pelos psicólogos, pela assistente social e pela agente de saúde.

Percebemos que há tensões entre os membros da equipe no sentido de buscar ampliar o campo de ação da saúde da mulher para além do âmbito da concepção biologizante, incluindo abordagens do âmbito das ciências sociais ou humanas.

Mendes-Gonçalves 13 (p. 40-1) esclarece que esses dois campos - o das ciências sociais e humanas e o da sociologia - tendem mais facilmente a "entrar em conflito com a orientação individualizante e biologizante da concepção da 'doença', devido aos seus específicos aportes sobre os fenômenos sociais e emocionais; no entanto, termina por orientar seu trabalho sob a normatividade médica, mantendo a abordagem individualizante".

Verificamos que há um movimento para executar ações com a finalidade da integralidade da atenção, interdisciplinaridade das técnicas e interação entre os profissionais da equipe; porém, falta uma intencionalidade em direção a um trabalho interativo.

\section{Discussão}

Este movimento de ir do concreto dado ao concreto pensado permitiu-nos evidenciar um conflito permanente em torno da organização interna das práticas de saúde, no planejamento familiar e, em particular, no processo de decisão pela ligadura de trompas.

Na organização geral da equipe, o médico detém espaço de poder, visto que lhe cabe a ação diagnóstica, terapêutica, cirúrgica e de coordenação da equipe, caracterizando-se como um trabalho hierarquizado, parcelado, subdividido. O trabalho dos demais profissionais é complementar, interdependente, delegado em graus de complexidade diferentes, ora integrado, ora desarticulado.

A ação na atenção à saúde da mulher reproduz as relações de poder presentes na construção do saber médico, perdendo a oportunidade de construir um saber coletivo, com base nos múltiplos saberes - o dos membros da equipe e o da mulher que freqüenta o serviço de saúde. O conjunto de ações é desenvolvido por uma equipe, mas não em equipe.

Observamos, contudo, que, apesar de o modelo não superar o recorte biológico sob o qual a mulher é concebida, há trabalhos que repre- sentam uma postura mais humanística, apontando para transformações. Há núcleos de resistência que mostram que alguns trabalhos tendem a se processar de forma diferenciada. Foi possível identificar dois momentos em que ocorre esse tipo de trabalho.

O primeiro é o trabalho de aconselhamento e orientação que a equipe realiza com a mulher que solicita laqueadura de trompas, quando procura abordar a mulher em seu contexto de vida e trabalho. Esse trabalho é mais freqüentemente realizado pelos psicólogos e pela assistente social. Observamos, neste caso, que mesmo que a equipe tenha tendência à horizontalidade, esta é apenas aparente, porque a equipe continua trabalhando, apesar de algumas resistências, no modelo biomédico e não chega a argüir sua racionalidade. Os profissionais têm dificuldades em valorizar os elementos da vida da mulher, que eles sabem, escutam e até consideram, mas não fazem valer.

O segundo momento é o da tomada de decisão da equipe sobre a laqueadura de trompas. Embora na organização do trabalho de atenção à saúde da mulher, em geral, o médico seja o detentor do processo de trabalho, destacamos que, no particular aspecto da decisão para a realização da cirurgia esterilizadora, ocorre certa horizontalidade da equipe, ainda que incomum. Essa horizontalidade pode ser explicada, primeiro, porque existem regras técnicas bem definidas e, segundo, porque o objeto de intervenção tem implicância ética importante e não só científica. A valorização da dimensão ética decisória tende a deslocar o saber do campo do conhecimento científico biomédico para um saber apoiado no conhecimento psicológico, sociológico e ético. Talvez por essa razão haja uma tendência à multiprofissionalidade evitando que o médico decida sozinho. Mas, por outro lado, e contraditoriamente, na tomada de decisão os critérios que fundamentam a decisão se apóiam no conhecimento biomédico, e não no sociológico, psicológico ou da ética de solidariedade à mulher.

Verificamos então que, a dimensão biomédica - o corpo, a doença, privilegia o critério técnico - uma forma tecnocrática de abordagem da mulher e a dimensão humanística, intersubjetiva, que permite a compreensão ampliada das mulheres, é colocada num segundo plano, muito embora as duas dimensões coexistam de forma indissociável e contraditória.

Tensões e conflitos estão presentes em vários momentos, de um lado, pela subordinação da prática à racionalidade biomédica, mas não do médico, e, por outro, pelo desejo, mesmo 
que incipiente, de superar esse modelo e fazer despontar um trabalho interdisciplinar.

Não há, entretanto, uma efetiva intercomunicação e interação com os profissionais da equipe de saúde. Almeja-se que a equipe utilize a comunicação como instrumento de trabalho de modo a articular as ações dos diversos profissionais.

Finalmente, ressaltamos que as discussões não permitem generalizações, visto que o estudo se limitou a uma equipe de saúde em particular.

\section{Resumo}

Este artigo contém parte dos resultados de uma investigação qualitativa cujo objetivo foi reconhecer as especificidades do trabalho da equipe de saúde que toma a laqueadura tubária como alvo de intervenção. Os dados empíricos foram obtidos por meio de entrevistas e de observações de algumas atividades dos nove agentes de uma equipe de saúde e submetidos à análise de discurso. Foram tomadas como categorias centrais para análise conceitos de processo de trabalho em saúde. Constatamos que, de modo geral, a equipe se caracteriza como hierarquizada. Destacouse que, no particular aspecto da tomada de decisão sobre a cirurgia esterilizadora, o trabalho da equipe de saúde tende à horizontalidade e ao trabalho multiprofissional. Nessa situação há uma valorização da dimensão ética decisória, deslocando o saber do campo do conhecimento biomédico para um saber mais compreensivo sobre a vivência das mulheres. Mas, por outro lado, e contraditoriamente, na tomada de decisão, os critérios que a fundamentam se apóiam no conhecimento biomédico e o saber mais compreensivo é colocado em segundo plano.

Laqueadura Tubária; Equipe de Assistência ao Paciente; Saúde da Mulher; Planejamento Familiar

\section{Referências}

1. Sociedade Civil Bem-Estar Familiar no Brasil. Pesquisa nacional sobre demografia e saúde, 1996. Rio de Janeiro: Sociedade Civil Bem-Estar Familiar no Brasil; 1997.

2. Secretaria de Assistência à Saúde. Portaria no 144 de 20 de novembro de1997. Brasília: Diário Oficial da União, 1997.

3. Secretaria da Assistência à Saúde. Portaria no 048 de 11 de fevereiro de 1999. Brasília: Diário Oficial da União; 1999.

4. Marcolino C. Análise do trabalho de uma equipe de saúde acerca da laqueadura tubária - estudo de caso de Belo Horizonte [Tese de Doutorado]. São Paulo: Faculdade de Saúde Pública, Universidade de São Paulo; 2000.

5. Campos GWS. Subjetividade e administração de pessoal: considerações sobre modos de gerenciar trabalhos em equipes de saúde. In: Merhy EE, Ocko R, organizadores. Agir em saúde: um desafio para o público. São Paulo: Hucitec. p. 229-66.

6. Gelbcke FL. Processo de trabalho em saúde e na enfermagem. In: Horr L, Sousa ML, Reibnitz KS, organizadores. Fundamentando o exercício profissional do técnico em enfermagem. Florianópolis: Universidade Federal de Santa Catarina, Centro de Ciências da Saúde, Departamento de Enfermagem, Departamento de Saúde Pública; 1999 p.153-176. 
7. Peduzzi M. Equipe multiprofissional de saúde: a interface entre trabalho e interação [Tese de Doutorado]. Campinas: Faculdade de Ciências Médicas, Universidade Estadual de Campinas; 1998.

8. Fiorin JL, Savioli FP. Para entender o texto. São Paulo: Editora Ática; 1997.

9. Car MR, Bertolozzi MR. O processo da análise de discurso. In: Chianca TM, Moraes MJA, organizadores. A classificação internacional das práticas de enfermagem em saúde coletiva: CIPESC. Brasília: Associação Brasileira de Enfermagem; 1999. p. 348-55. (Série didática: enfermagem no SUS).

10. Peduzzi M, Schraiber LB. Recursos humanos e trabalho coletivo em saúde: a equipe multiprofissional. Washington, DC: Organização Pan-Americana da Saúde; 1999.

11. Schraiber LB. Medicina tecnológica e prática profissional contemporânea: novos desafios, outros dilemas [Tese de Livre Docência]. São Paulo: Faculdade de Medicina, Universidade de São Paulo; 1997.

12. Mendes-Gonçalves RB. Práticas de saúde e tecnologia: contribuição para a reflexão teórica. Brasília, DF: Organização Pan-Americana da Saúde; 1988.
13. Mendes-Gonçalves RB. Práticas de saúde: processos de trabalho e necessidades. São Paulo: Centro de Formação dos Trabalhadores em Saúde, Secretaria Municipal da Saúde de São Paulo; 1992 (Cadernos CEFOR 1 - Série textos).

14. Mendes-Gonçalves RB. Tecnologia e organização social das práticas de saúde. São Paulo: Hucitec; 1994.

15. Almeida MCP, Mishima SM, Silva E, Mello DF. O trabalho de enfermagem e sua articulação com o processo de trabalho em saúde coletiva - rede básica de saúde. In: Almeida MCC, Melo SM, organizadores. O trabalho de enfermagem. São Paulo: Cortez; 1997. p. 61-112.

16. Schraiber LB, Peduzzi IM, Sala A, Nemes MIB, Castanheira ERL, Kon R. Planejamento, gestão e avaliação em saúde: identificando problemas. Ciênc Saúde Coletiva 1999; 4: 221-42.

Recebido em 19/Nov/2002

Versão final reapresentada em 22/Out/2003

Aprovado em 30/Out/2003 